\title{
Research on the Scientific Instruments Management which Combined Multilevel Sharing with Self-Hosting
}

\author{
Huang Zhengjun ${ }^{\mathrm{a}}$, Zhang Lei, Song Weidong, Liu Yu, Zhang Dong, Liang Wei \\ School of Civil Engineering and Resources \\ University of Science and Technology Beijing \\ Beijing, 100083 \\ a huang_jun.0518@163.com
}

\begin{abstract}
Opening, sharing and efficiently managing scientific instruments can increase their utilization and specialization. It also attaches great importance to optimizing resources allocation, enhancing the capacity of independent innovation and quality of the scientific research in universities. We should establish sound mechanism of opening and sharing scientific instruments, policy and system to manage them and platform shared by universities, institutions and departments about purchasing scientific instruments and equipment. We also should set up the management pattern combined self-hosting with the operation and maintenance of the instruments, as well as measures like sharing equipment and management safeguard system. Through these ways, we can improve the innovation capacity and usage rate of scientific instruments in universities and colleges, further enhancing the ability and quality of science and rese arch in schools.
\end{abstract}

Keywords-scientific instruments; opening and sharing; system of allowable purchase; management pattern

\section{INTRODUCTION}

Recently, as more funds are invested into education and the cost of scientific research is increasing rapidly, fixed assets like instruments and equipment grow greatly, of which the scientific ones account for a modest portion. Taking the school of civil engineering and resources, University of Science and Technology Beijing as an example, it now owns large-scale equipment worth over 400 thousand Yuan more than 110 and over 3500 common equipment, whose total value reaches 96 million Yuan. Among these instruments, more than 1000 ones are purchased by teachers using their own scientific research funds. The improvement of scientific instruments, on the one hand, significantly promotes scientific research. On the other hand, it also exposes many problems in the management of instruments, such as duplicate procurement and low service efficiency caused by barriers in sharing. If we fail to improve these problems, it would lead to the waste and loss of scientific funds and restrict the further development of scientific research in universities and colleges[1-2].

We conduct the research into the management pattern of sharing scientific instruments and promote their paid sharing. It can increase the utilization and specialization of the equipment,

Foundation Item: the Fundamental Research Funds for the Central Universities (FRF-OT-18-013SY) activate idle scientific resources and relieve some instruments from overload, so as to efficiently avoid duplicate procurement, save funds of purchasing equipment and invest them into innovation activities. It also can promote the professionalization of applying scientific instruments, increase the income from sharing equipment, which can save up for the technicians and maintenance. It could proactively facilitate the collaborative innovation in universities and the whole society, and enhance the creative achievements' efficiency and level of specialization. Significant role is played in optimizing allocation of resources, enhancing the capacity of independent innovation and increase scientific research quality[2-4].

\section{CuRRent Situation AND TENDENCy OF THE MANAGEMENT OF SHARING SCIENTIFIC INSTRUMENTS AT HOME AND ABROAD}

Nowadays, some developed countries like the United States establish clear and specific management system, which enjoys distinct purchase procedure, clear ownership of the property and rational sharing mechanism. The British Government sets up specific administration to regulate the sharing of scientific instruments, strictly control their property, but conduct supportive policy for sharing service that offers discount, such as the projects for the purpose of academic study have free access to the instruments and providing accommodation allowance and limit funds for lab materials. Germany conducts the pattern combined strict approval of purchase and comprehensive system of opening and sharing. Japan and Korea introduce related policies to preferentially approve equipment considering social sharing and special regulations to guarantee their opening and sharing, while offering professional technicians. However, these methods mainly concentrate on the sharing and management of large scientific instruments[4-6].

"National R\&D Infrastructure and Facility Development Outline of China in 2004-2010" points out that we should focus on constructing sharing mechanism. Notification of the Ministry of Education on Issuing Regulations on Instruments and Equipment in Universities and Colleges([2000]No.9) also requires that the instruments should be managed and maintained by special institution and be used and shared by all departments[6-8]. At present, China has gradually formed a 
situation that the scientific instruments shared by the nation, regions, provinces and cities[8-10], while the whole country has formed a overall layout that integrates point and sphere and coupling development. In terms of the regions, we have already had seven regional synergistic networks, namely Bohai Rim, Northeast, Northwest, Yangtze River Delta, Southwest, Central China and Pan-Pearl River Delta. They adopt effective measures to integrate the innovative resources in each region, promoting the growth of the innovative capacity. Provinces and Cities also set up platforms sharing science and technology, for example, Beijing has The Capital Sci\&Tec Resources Platform. However, these concentrate on the sharing and management of large-scale equipment, failing to cover the common, mediumand small-scale instruments and equipment.

Some universities and colleges also establish their own sharing platforms and systems and put forward relevant theories to manage the equipment and train technicians. Nonetheless, most theories and researches focus on the sharing of large instruments, instead of the common ones, which is used by teachers and graduates in their research. Therefore, it is necessary to set up a series of theory and practical system for all scientific instruments.

\section{IDEAs About Sharing And MANAging ScIENTIFIC INSTRUMENTS}

\section{A. Establish Policies and Regulations of Opening and Sharing Scientific Instruments}

Opening, sharing and efficiently managing scientific equipment should first establish rational policy and regulation in our nation, provinces, cities, universities and colleges, so as to make sure that we can conduct the opening and sharing of scientific instruments. Opinion of the State Council on Opening Major Scientific Infrastructure and Large Scientific Instruments to the Public published by the state in 2014, Management Method of the National Scientific Resources Sharing Service Platform, Works about Further Conducting the Opening and Sharing of Major Scientific Infrastructure and Equipment, Notification of Examining and Evaluating the Opening and Sharing of the Major Scientific Infrastructure and Instruments in Central Universities and Research Institutions, Suggestions on the Implementation of Constructing the Capital Sci\&Tec Resources Platform to Further Promoting to Opening Major Scientific Infrastructure and Instruments to the Public, these regulations could guide us to formulate policies to share and manage scientific equipment.

Meanwhile, our school also published Regulations about Opening and Sharing the Instruments and Equipment in University of Science and Technology Beijing(on trail), Regulations about the Maintenance Funds of the Equipment in University of Science and Technology Beijing, Interim Management Procedures of Placing and Using Equipment Outside of the University of Science and Technology Beijing and other rules and regulations; in May 2018, our school issued Project about Using the Equipment from the Laboratory of the School of Civil Engineering and Resources and the Public Maintenance Funds(discussion draft). Above rules and regulations provide policies and practical basis for building multilevel opening, sharing and management system of scientific instruments.

\section{B. Exploring to Setup an Opening Platform of Scientific Instruments Shared by the University, Institution and Department}

We should explore to set up the diversified system to open and share scientific instruments, integrate the resources from departments, institutions and universities, through which we can set up different platforms to manage and share scientific equipment from them. At the meantime, we should lay emphasis on supporting the opening and sharing of national major laboratories and scientific equipment in engineering center.

On the basis of asset management system and sharing platform of large equipment, school should further establish "online platform for opening and sharing scientific instruments in universities", which includes their basic information, property ownership, main function, real-time situation, online appointment, usage record, cost and achievements. Meanwhile, on this premise, the institution could set up sharing platform or system of scientific equipment, open the sharing service to other departments or social organizations on the condition that the departments and institutions can share and use; under this premise, the department should establish inner sharing platform. These instruments can be used and shared according to the order of purchaser, research group, institution, university and society. Thus, we could decrease duplicate procurement of the instruments and increase their efficiency and output benefits.

\section{Establish Healthy Procurement Mechanism of Scientific Equipment}

On the basis of current procurement management of the equipment, we should establish and complete the purchasing mechanism and conduct verifying system approved by university, institution and department.

First of all, the departments and research center should verify the purchasing plans raised by laboratories, and evaluate their necessity and feasibility according to the list, condition and requirements of current equipment. Then the condition of current equipment and the necessity of buying new ones should be clarified. Second, the institution should review the procurement plans given by the departments. Based on the opinion of primary examination and storage condition and financial sources, the institution reviews the plans and submits to the asset management office. Finally, the university decides whether to make the purchase or not, and demonstrates the kindred scientific instruments that are raised by many people at the same time or already existed. Then negotiation should be conducted by managers, potential purchasers and buyers who once bought the machine. They should discuss the possibility and feasibility of jointly buying and using equipment, and coordinate the shared problems with different organizations in the process of procurement and management. 


\section{Establish the Maintenance and Management Pattern of Scientific Instruments Combined with Self-hosting}

The daily administration of scientific instruments could follow the pattern that they should be managed by their buyers or mandated by lab center. Details should be decided by the purchasers and fund principals in response to the circumstances. The final goal is to make our scientific equipment be responsible for specific personnel, so as to guarantee its normal operation, opening and sharing.

In terms to the maintenance of equipment, we should implement rules like appointment, registration, doing appropriate payment and sharing achievements. When it comes to the charge, we should first follow the premise of servicing for instructional demands, explore to implement the method that buyers, undergraduate and graduate education use the equipment for free, while the research group could be derated, other intramural group could enjoy discount and we should charge social organization normally. Those who are responsible for the equipment or subjects should administrate the expense, which could use as the funds to repair and change machine, as well as train and hire personnel. Before sharing the instruments, potential users should take professional training. We should estimate and record after their usage, in order to guarantee the normal operation of the instruments and provide basis for the operation and perfection of the regulation.

\section{E. Setting up Mechanism to Open, Share and Manage Scientific Equipment}

To efficiently conduct the opening, sharing and management of scientific instruments, we should set up relevant organization and evaluation system and other security mechanism. On the premise of the policy and regulation, we should set up relevant organization. The university, institution and department should establish groups to share and manage scientific instrument, while the leaders should run the groups and plan the opening, sharing and management of the equipment. Meanwhile, examination and evaluation system and incentive mechanism should be conducted on equipment and managers. Then we should encourage teachers and researchers to open and share the equipment and further develop its functions. In addition, we should praise and award the organization and person who owns equipment that enjoys high efficiency, benefits, new functions and achievements and can manage it well. We also should fully mobilize the procurement and managers, so as to increase the benefits of the equipment [11-13].

\section{CONCLUSION}

Scientific instruments are the important foundation of scientific research and technology innovation. Its application and benefit is also the significant sign to measure a nation's development level and potential in science and technology.
This article mainly studies the content of the sharing system, constructing platform and management model, which includes setting up healthy mechanism to open and share the equipment and platform used by university, institution and department. We research the object, priority order of the instruments, ways of charging and serviceable range. Meanwhile, we should set up the procurement system, management model of the equipment's operation, maintenance and self-hosting, as well as the opening, sharing and safeguard system. Therefore, we can enhance the innovative ability and utilization of scientific instruments, further increasing the service capacity and quality of the scientific research in institutions and departments.

\section{REFERENCES}

[1] Ren Chunxiu. Research on the Opening and Sharing System of the Scientific Instruments in Universities and Colleges[J]. Enterprise Science And Technology \& Development, 2014, (07):144-145.

[2] Zhang Tianli, Xu Dahai, Shen Yanbin. Research on the Realization Route for Opening and Sharing of Scientific Instruments and Equipment[J]. Research and Exploration in Laboratory, 2015, 34(03):274-278.

[3] Cai Bing, Liu Shuling, Yin Lingna, Wang Xuejiang. Exploration and Practice on the Opening-up and Sharing of Large-scale Apparatus and Equipment in Universities[J]. Research and Exploration in Laboratory, 2014, 33(02):259-263.

[4] Li Wenjuan, Zhong Minjian. Design and Accomplishment of the Valuable Instruments and Equip ment Sharing Platform in Universit ies[J]. Research and Exploration in Laboratory, 2013, 32(08):461-464.

[5] Huang Zonghui, Lu Haitao, Luan Changping, Li Xijian. Countermeasures on the Sharing and Management of the Instruments and Equipment in Universities[J]. Research and Exploration in Laboratory, 2014, 33(04):72-76.

[6] Ying Weifeng, Gao Yan, Zhao Huiwu. Research on Some Problems of Large-scale Instruments and Equipment Sharing[J]. Experimental Technology and Management, 2011, 28(11):213-216.

[7] Diao Shujun. Discussion on the Mechanism of Sharing and Management of Large Instruments and Equipment in Colleges and Universities[J]. Experimental Technology and Management, 2010, 27(07):194-196.

[8] Liu Li, Gu Fengqi, Li Dcai. Sharing Mechanism of the Teaching and Scientific Instruments and Facilities in Universities[J]. Research and Exploration in Laboratory, 2010, 29(07):336-338.

[9] Fan Yiwen, Yu Yongqiang. Brief Analysis on Sharing Management for Instruments and Equipment in Research Laboratories of Colleges[J]. Experiment Science and Technology, 2011, 9(04):163-165.

[10] Gong Meijuan, Sun Xinglian, Xu Qinping, Meng Qingru. Exploration on Constructing the Platform of Opening, Sharing and Management of the Instruments and Equipment in Universities and Colleges[J]. Journal of Jiangsu Institute of Education(Natural Sciences), 2012, 28(04):49-51.

[11] Yang Shuai, Ren Jinni. Innovating the Management Model and Operational Routine for Large Equipment[J]. Experimental Technology and Management, 2007, 24(2):157-158, 162.

[12] Song Lirong, Liu Chunxiao. Summary and Analysis of Large-scale Scientific Instruments Resource Opening-sharing Project Construction of China[J]. China Basic Science, 2014(03):16-21.

[13] Shi Tiangui, Zhou Yong, Peng Shaochun, Zhang Jixia. Emphasis on the Incentive Mechanism to Promote the Opening and Sharing of Instruments and Equipment[J]. Experimental Technology and Management, 2015, 32(03):10-12. 